UDC 621.369 .9

\title{
TEMPERATURE DEPENDENCE OF THE BACKSCATTERING COEFFICIENT MEASURED BY ALOS PALSAR DURING COOLING AND HEATING OF TUNDRA TOPSOIL
}

\author{
K. V. Muzalevskiy \\ Kirensky Institute of Physics Federal Research Center KSC SB RAS, \\ 660036 Krasnoyarsk, Russia
}

The paper is received on November 7, 2019

\begin{abstract}
In this paper, dependences of backscattering coefficient on Arctic tundra soil temperature were investigated. The backscattering coefficient was measured by ALOS PALSAR (1.3GHz) over areas near to Imnaviat weather station in the North Slope of Alaska in the period from January 12, 2009 to April 20, 2011. It has been experimentally and theoretically shown that there is a strong correlation relationship no worse than 0.76 between the surface soil temperature measured by weather stations and backscattering coefficient. The variations of the backscattering coefficient was found to be about 5-6 dB over the test site when soil surface temperature changes from $-10^{\circ} \mathrm{C}$ to $10^{\circ} \mathrm{C}$. This study contributes to further understanding the processes of scattering of frozen Arctic soils that is pertinent to developing new remote sensing algorithms for the permafrost region.
\end{abstract}

Key words: ALOS PALSAR, backscattering, active layer, topsoil temperature.

\section{Introduction}

The surface soil temperature, soil moisture, permafrost thermal state and timing of the seasonally frozen and thawed states of the soil surface are included in the fiftyfour essential climate variables recommended by the World Meteorological Organization for observation [1]. These parameters-indicators which are may capable characterizing the integrated impact of anthropogenic and natural factors on the Arctic ecosystem. At the same time, especially in the Arctic region, weather station networks are too sparse to provide enough data to climatic models about soil 
temperature, soil moisture and permafrost state. Modern remote sensing satellites passing close to polar orbits can observe up to several times a day extensive arctic areas with high spatial resolution. They are an additional source of independent data, complementing the highly sparse ground-based measurements of meteorological stations. At the same time, insufficient knowledge of the processes of microwave scattering by the Arctic tundra soils are hindered remote sensing of these parameters because of a significant error in their measurement in polar regions [2]-[5]. In this paper, the dependences of radar backscattering in the L-band on the soil temperature during cooling and heating of the frozen active layer were investigated at test sites in the Arctic tundra. These temperature dependences are related to the phase transitions of water in the process of cooling and heating of frozen soil [6]. Temperature dependences of complex permittivity (CDP) are well studied during the thawing and freezing of soil samples with a high content of organic matter in laboratory conditions [6]. Such temperature-dependent changes in CDP can to provide measuring not only the thawed or frozen soil states, but also to determine content of unfrozen water and ice, as well as temperature of frozen soil during it cooling and heating process. Before, the temperature dependence of the backscattering coefficient, measured by Sentinel-1 and Radarsat, for mineral soils of moderate latitudes was studied in [7], [8] and for Arctic region [9]; for the Arctic region, studies like that were not performed in L-band.

\section{Test site and satellite data}

The areas next to Imnaviat weather station (IMS) in the North Slope of Alaska (NSA) was selected as Arctic tundra test site. The coordinates of IMS is (68.639656,149.352341). IMS site are located on the inner coastal plain not far from river terraces. Landcover units in the IMS area include the prostrate dwarf shrub and Salix arctica, Graminoid-moss tundra and graminoid, prostrate-dwarf-shrub, moss tundra (wet and moist nonacidic). Time series data of soil temperature and moisture for the active layer, air temperature and snow depth has been recorded for this site over a relatively long period (2008-2017) [10]. In this paper, ALOS PALSAR observations 
( $1.26 \mathrm{GHz}$, incidence angle of $\sim 20-42^{\circ}$ ) covered the period from January 12,2009 to April 20, 2011 were used. For these periods 120 radar images were analysed. Radar backscattering for the IMS test site was acquired from GRD Level-1.5 ALOS PALSAR. Product with (100m spaced medium resolution) FBS sensor mode, passes about 21:00 (UTC) and HH-pol were used. The radar images were processed in the Sentinel Application Platform (SNAP) according to the procedure: radiometric calibration, speckle filtering ( $5 \times 5$ mean filter) and incidence angle normalization (reference angle $30^{\circ}$ ).

\section{Radar backscattering coefficient depending on temperature of frozen arctic topsoil during of it's cooling and heating}

In the area of the IMS weather station, the temperature dependence of the radar backscattering coefficient measured by ALOS PALSAR relative to the soil surface temperature measured by the weather station is depicted in Fig. 1.

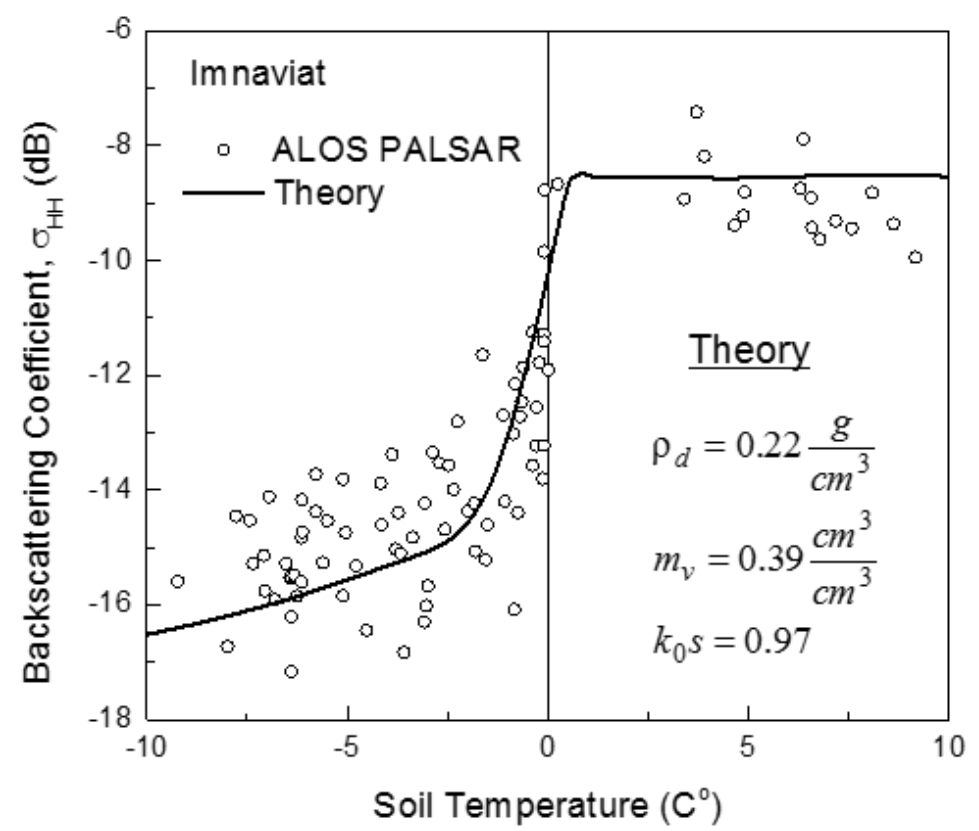

Fig. 1. Dependence between the ALOS PALSAR backscattering coefficient and the soil surface temperature $(0-1 \mathrm{~cm})$ in the area of IMS weather station.

The backscattering depends on the soil temperature (see Fig. 1) can be explained temperature dependence of the permittivity of organic-reach tundra soil. In the process of freezing (surface soil temperature less than ones at the depth), as the 
temperature of frozen soil decreases, the volumetric content of transition water decreases, but the ice content increases. These processes lead to a decrease in the soil permittivity and, consequently, in the reflectivity or backscattering coefficient of the soil as the surface soil temperature decreases (see Fig. 1).

To analyse the radar backscattering variations, Oh's model [11] was used under the assumption of a dielectrically homogeneous active topsoil, without taking into account wave scattering and attenuation in the snow pack and vegetation canopy, and we did not consider the profiles of the permittivity and temperature in the active layer of frozen soil:

$$
\begin{aligned}
& \sigma_{H H}=g \sqrt{p} \cos ^{3} \vartheta\left[R_{V}\left(\vartheta, \varepsilon_{s}\right)+R_{H}\left(\vartheta, \varepsilon_{s}\right)\right], \\
& g=0.7\left(1-e^{-0.65 k_{0} 0^{1.8}}\right), \\
& \sqrt{p}=1-(2 \vartheta / \pi)^{0.314 / R_{0}\left(\varepsilon_{s}\right)} e^{-k_{0} s},
\end{aligned}
$$

where $\vartheta$ is the incidence angle in radians, $R_{H, V}\left(\vartheta, \varepsilon_{\mathrm{s}}\right)$ is the Fresnel reflection coefficient on horizontal and vertical polarizations, $\varepsilon_{\mathrm{s}}=\varepsilon_{\mathrm{s}}\left(\rho_{d}, m_{v}, T_{s}, C\right)$ is the soil complex permittivity, $\rho_{d}$ is the soil bulk dry density, $m_{v}$ is the volumetric soil moisture, $C$ is the soil texture factor (clay or organic content), $T_{s}$ is the surface soil temperature, $R_{0}=R_{H, V}(\vartheta=0), k_{0}$ is a free space wave number, and $s$ is the root-meansquare deviation of the soil surface height. We will try to theoretically describe the experimentally established temperature dependence of the backscattering coefficient due to only the temperature variations of the surface soil permittivity. To this end, the inverse problem relative to soil moisture, $m_{v}$, dry bulk density, $\rho_{d}$, and roughness parameter, $k_{0} s$, of the soil surface using $O h^{\prime} s$ model (1) was solved for the IMS test site. At this the residual norm between the time series of the backscattering coefficient measured by ALOS PALSAR and the calculated ones was minimized for all available data, including both thawed and frozen soil. The backscattering coefficients were calculated on the basis of the IMS weather station soil surface temperature $(0-1 \mathrm{~cm})$ data, model (1), and the dielectric model [6], neglecting snow cover $(\sim 0.4 \mathrm{~m}$ in depth, which is mainly dry in winter and it is transparent 
environment for L-band). Thus, the calculated reflection coefficient for the optimally found parameters as a function of the soil surface temperature is depicted in Fig. 1 (solid line). The retrieved value of the soil dry bulk density $\left(0.22 \mathrm{~g} / \mathrm{cm}^{3}\right)$ corresponds to the ones observed in the organic topsoil in actual tundra conditions. Relative to an average soil moisture of $~ 0.32 \mathrm{~cm}^{3} / \mathrm{cm}^{3}$ measured by the IMS weather station at a depth of $14 \mathrm{~cm}$ in the period 2010-2011, the retrieved soil moisture value $\left(0.39 \mathrm{~cm}^{3} / \mathrm{cm}^{3}\right)$ correlates very well. The retrieved value of root-mean-square deviations of the soil surface heights $(s=0.04 \mathrm{~cm})$ corresponds to a rough landscape in the vicinity of the IMS weather station installation. The correlation coefficient between the measured and retrieved values of the backscattering coefficient in the negative temperature region was found to be equal to 0.76. As can be seen from Fig. 1 , the most significant deviations of the measured value of backscattering coefficient from the calculated ones are observed in the temperature range from $-5^{\circ} \mathrm{C}$ to $-0^{\circ} \mathrm{C}$. From our point of view, the gradients of permittivity and temperature observed at this time in the active topsoil contribute significantly to the wave reflection and were not taken into account in the model (1). It can also be concluded that the temperature dependence of the backscattering coefficient for arctic tundra soil can be described with a good degree of accuracy only due to temperature changes in the dielectric permittivity of the Arctic tundra topsoil, which is reach in organic matter.

\section{Conclusion}

In this paper, the temperature dependences of the backscattering coefficient, measured by ALOS PALSAR, in the process of the heating and cooling of frozen soil for typical tundra test site located in the North Slope of Alaska near Imnaviat meteorological station were investigated. As a result, it was shown that in the range of soil surface temperature changes from $-10^{\circ} \mathrm{C}$ to $0^{\circ} \mathrm{C}$, the variations of the backscattering coefficient are about 5-6 dB for test site. It is shown that these changes are mainly due to the temperature dependence of the soil permittivity with a high content of organic matter. The experimentally confirmed temperature dependence of the backscattering coefficient based on satellite observations opens up the possibility 
of measuring such important parameters as the unfrozen water content in frozen Arctic soil, and more accurate approaches to identifying frozen and thawed soil states can be developed. In addition, the possibility of estimating the annual average parameters such as soil density, surface soil moisture and roughness has been demonstrated. Further research for other test sites should be planted in order to investigate the possibility of establishing like temperature dependencies for different landscape conditions in the Arctic tundra region.

\section{Acknowledgement}

The study was performed thanks to the Program of SB RAS (project №03562019-0004), JAXA project No. PI 1422002.

\section{References}

1. World Meteorological organization [Online]. Status of the Global Observing System for Climate (GCOS-195), October 2015. Available at: http://www.wmo.int/pages/prog/gcos/Publications/ GCOS-195_en.pdf.

2. Rautiainen K., et al. SMOS prototype algorithm for detecting autumn soil freezing. Remote Sensing of Environmen. 2016. Vol.180. P.346-360.

3. Al-Yaari A. et al. Global-scale evaluation of two satellite-based passive microwave soil moisture datasets (SMOS and AMSR-E) with respect to Land Data Assimilation System estimates. Remote Sensing of Environment. 2014. Vol.149. P.181-195.

4. Roy A. et al. Response of L-Band brightness temperatures to freeze/thaw and snow dynamics in a prairie environment from ground-based radiometer measurements. Remote Sensing of Environment. 2017. Vol.191. P.67-80.

5. Muzalevskiy K. V., Z. Ruzicka. Retrieving Soil Temperature at a Test Site on the Yamal Peninsula Based on the SMOS Brightness Temperature Observations. IEEE Journal of Selected Topics in Applied Earth Observations and Remote Sensing. 2016. Vol.9. No.6, P.2468-2477.

6. Mironov V.L., Savin I.V. A temperature-dependent multi-relaxation spectroscopic dielectric model for thawed and frozen organic soil at $0.05-15$ 
GHz. Physics and Chemistry of the Earth, Parts A/B/C. 2015. Vol.83-84. P.5764.

7. Rodionova N.V. Sentinel-1 data correlation with ground measurements of soil temperature. Sovremennye problemy distantsionnogo zondirovaniya Zemli iz kosmosa Modern Problems of Remote Sensing of Earth from Space. 2017. Vol.14. No.5. P.135-148. (In Russian)

8. Khaldoune J., et al. An approach for mapping frozen soil of agricultural land under snow cover using RADARSAT-1 and RADARSAT-2. IEEE Geoscience and Remote Sensing Symposium Proc. 2008. Vol.3. P. III-382-III-385.

9. Radionova N.V. Backscattering from the near-surface layer of thawed/frozen soils of alaska from Sentinel-1 radar data. RENSIT. 2019. Vol.11, No.1, P.2130.

10. Permarfrost Laboratory University of Alaska. [Online]. Database. Available at http://permafrost.gi.alaska.edu/site/im1.

11. Y. Oh, K. Sarabandi and F. T. Ulaby. An empirical model and an inversion technique for radar scattering from bare soil surfaces. IEEE Transactions on Geoscience and Remote Sensing. 1992. Vol.30. No.2. P.370-381.

\section{For citation:}

Muzalevskiy K.V. Temperature dependence of the backscattering coefficient measured by ALOS PALSAR during cooling and heating of tundra topsoil. Zhurnal Radioelektroniki - Journal of Radio Electronics. 2019. No. 11. Available at http://jre.cplire.ru/jre/nov19/19/text.pdf DOI 10.30898/1684-1719.2019.11.19 